\title{
SPATIAL ANALYSIS OF ANNUAL AND SEASONAL SUNLIGHT VARIATION THROUGH GIS KRIGING TECHNIQUE
}

Asim Nawaz
Department of Geography University of Karachi. Karachi (Pakistan)
E-mail: asimpmd@gmail.com

Sikandar Ali

Indus University. Karachi (Pakistan) E-mail: sikandar.shah@indus.edu.pk

Sabir Ali Kalhoro

Department of Electronics Engineering NED University of Engineering and Technology. Karachi (Pakistan) E-mail: sabir13es66@gmail.com

Saadullah Rahoojo Department of Geography, University of Sindh. Jamshoro (Pakistan) E-mail:rahoojosaad@gmail.com

Muneer Abbas

Department of Energy and Environment Hamdard University. Karachi (Pakistan) E-mail:10memuneer@gmail.com

Muhammad Shahid Department of Electronic Engineering, Dawood University of Engineering \& Technology. Karachi (Pakistan) E-mail: engr_shahid82@yahoo.com

Recepción: 05/03/2019 Aceptación: 19/03/2019 Publicación: 17/05/2019

\section{Gitación sugerida:}

Nawaz, A., Ali, S., Ali Kalhoro, S., Rahoojo, S., Abbas, M. y Shahid, M. (2019). Spatial Analysis of Annual and Seasonal Sunlight Variation through GIS Kriging technique. $3 C$ Tecnología. Glosas de innovación aplicadas a la pyme. Edición Especial, Mayo 2019, pp. 468-485. doi: http://dx.doi.org/10.17993/3ctecno.2019.specialissue2.468-485

Suggested citation:

Nawaz, A. Ali, S., Ali Kalhoro, S., Rahoojo, S., Abbas, M. \& Shahid, M. (2019). Spatial Analysis of Annual and Seasonal Sunlight Variation through GIS Kriging technique. 3C Tecnología. Glosas de innovación aplicadas a la pyme. Special Issue, May 2019, pp. 468-485. doi: http://dx.doi.org/10.17993/3ctecno.2019.specialissue2.468-485 


\section{ABSTRACT}

Today the developing countries are facing multiple types of crises especially in the term of energy crises. Also Energy has great worth because it is very essential for the development of any society as well as for the adequate standard of living, every country requires the energy i.e. Electricity, as to carry out the basic activities, however as the population is increasing rapidly so the demand for energy (electricity) is also increasing and if the required demand for energy is not supplied then it creates the energy shortage, therefore we require the alternative resources (solar energy), to control the energy crises. Sunlight has a lot of importance because it is a renewable resource and is the best alternative to control the energy crises.

Pakistan is a country which is facing energy crises. These crises take the serious shape of torment in the summer season, especially in Sindh province. However, due to its geographical location, the province receives a sufficient quantity of sunlight in the whole year.

In this research, our focus is to spot the most appropriate locations for the efficient utilization of solar energy in different seasons, based on pointed data, derived from different meteorological observatories over the last thirty years. And with the help of Geographic information system, the annual average sunlight of the province has been observed which is $8.5 \mathrm{hrs} /$ day and the central part of the province is spotted, which is more suitable for solar plants because the temperature remains high in this part.

\section{KEYWORDS}

Sunlight, Spatial Variation, Pointed Data, GIS, Kriging Interpolation. 


\section{INTRODUCTION}

Pakistan is a developing country having a high growth rate of population, which has created multiple types of problems in-spite of these troubles, God has bestowed with many blessings among them, its geographical location is one and more important, and due to its location it is the richest country in the world in terms of solar energy, which receives the yearly global irradiance of 1900-2200 kW hr/m2 (Asif, 2009; Bakhtiar \& Ahmed, 2017). Most area of country, mainly Baluchistan, Sindh, and southern Punjab get plentiful solar irradiation approximately 2 MW $\mathrm{hr} / \mathrm{m} 2$ and $3000 \mathrm{hrs}$ of sunlight per year, which is the great average amount of solar radiation in the world (Ahmed, Zafran, Khan, Waqar \& Hasan, 2017; Tahir \& Asim, 2018). Pakistan has predictable solar energy more than 100,000 MW (Basir, Aziz, Ahmad \& Wahid, 2013). Sunlight carries radiant energy to the surface of the earth. The sunrise to sunset is the duration of sunlight of any place and its amount is badly influenced by various factors including clouds, humidity, air pollution, latitudinal and altitudinal location, physical relief, annual march of the sun, and length of the day. Just like other climatic components, sunlight is also valuable for human beings and other ecosystems. Various crops need short days (winter), while other need lengthy days (summer) and it is very essential for the photosynthesis process and flowering, thus, reasonable sunlight is necessary for the growth of plants as well as for human activities. The best alternate source of renewable energy is the sun. The solar energy is required for heating, lighting houses and other buildings as well as for the generation of electricity, and for different commercial and industrial activities.

The Solar Energy has the great potential for providing clean, safe, and reliable power; however it reaches on the surface of earth greater than 200 times the total annual commercial energy is being utilized by humans (Kabir, Kumar, Kumar, Adelodun \& Kim, 2018; Venkataraman \& Elango, 1998). Most of the rural areas where people are suffering from the energy crisis, solar energy can bring them a solution as it has some benefits as free energy source, free from pollution, used in remote areas and it can be stored in the battery. The people living in rural areas are approximately Ninety-seven million, which contains 7 million 
houses. As said by the International Energy Agency approximately 38 per cent population in Pakistan remain to deprive of electricity. While at present about $54 \%$ of rural population have not the availability of electricity, which causes to live sub-standard life of poverty and social inequity. Therefore the development of the country is being suffered as these areas possess an abundance of resources and workforce that is currently disengaged from the mainstream.

\section{STUDY AREA}

The study area is shown in (Figure 1). The Sindh province lies in the southeast of the country. Sindh is the 3rd largest province of Pakistan by area wise, which is further divided into 29 districts. The total area is approximately $140,915 \mathrm{~km}^{2}$ (Ahmed, et al., 2009). The latitude and longitude of the Sindh province are $25.8943^{\circ} \mathrm{N}$ and $68.5247^{\circ} \mathrm{E}$. The approximately yearly rainfall in the province is $150 \mathrm{~mm}$. The climate of a region is majorly influenced by rainfall and temperature.

The climate of the province varies from tremendously hot in the north to moderate in lower Sindh districts. In lower Sindh during the summer seasons in the months of May and June, the temperature reaches above 40 degree Celsius, and in winter seasons it remains 17 to 19 degree Celsius (Qasim, Luqman \& Khan, 2016). 


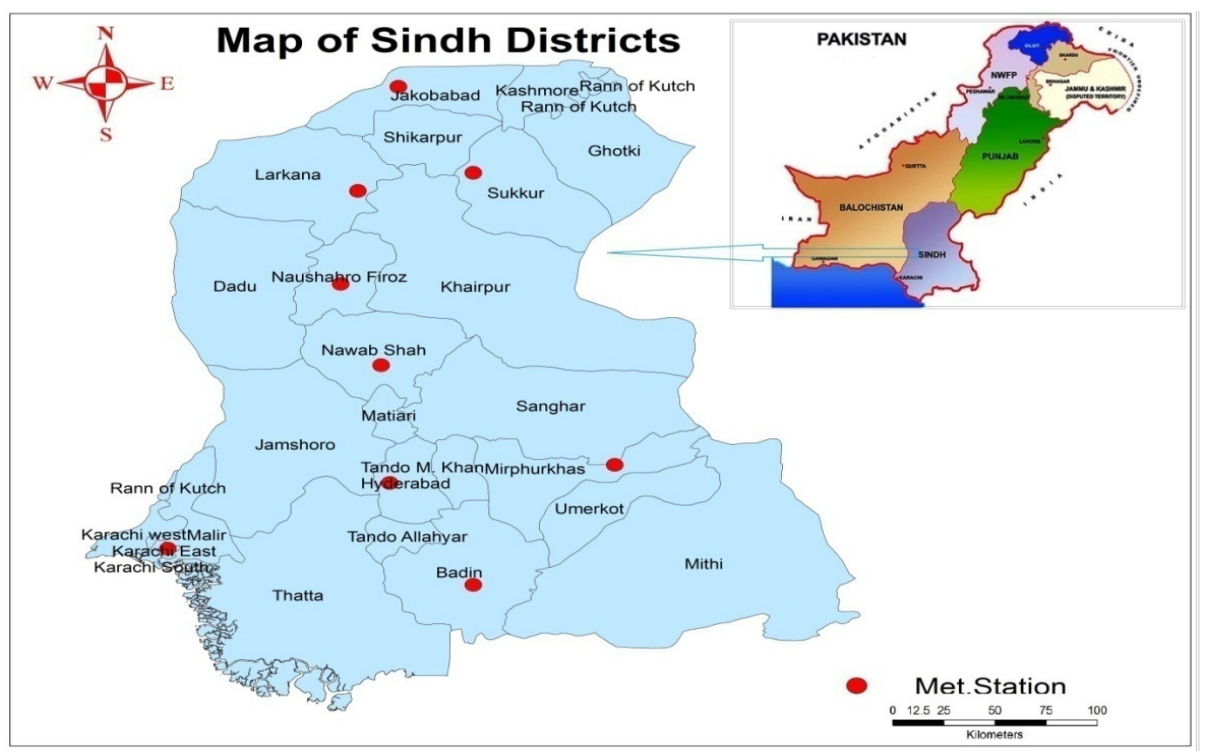

Figure 1. Map of the study area.

\section{METHODOLOGY}

This research work explains the annual and seasonal variation of sunlight in Sindh province and identifies area having the highest and lowest amount of sunlight in a year. The research is based on the meteorological weather observatories data which were collected from the Pakistan Meteorological Department. For the analysis of sunlight duration, the year has been divided into two major seasons such as summer and winter. The yearly and seasonal variation of sunlight duration of Sindh has been studied taking into account highest sunlight regions (higher than $9 \mathrm{hrs} /$ day), moderate sunlight regions (between $8 \mathrm{hrs} /$ day to $9 \mathrm{hrs} /$ day), and the lowest amount of sunlight regions (less than $8 \mathrm{hrs} /$ day).

The Kriging interpolation technique has been employed to generate a sunlight duration surface of the Sindh province. Kriging is generally used as a type of interpolation techniques, which estimates the outputs in the form of a linear combination of measured values, whose weights depend on the spatial correlation between them. Addition of weights is equal to 1 . While the previous postulation of this technique is that the spatial procedure should be postulated 
as inherent stationary, which means the raw data will not alter with space or time. Kriging assumes the distance or direction between sample points reflects a spatial relationship which can be used to describe a variation on the surface. The Kriging tool fits a mathematical function to a particular number of points, or all points within a particular radius, to determine the output value for each location.

The mathematical form of Kriging is shown in Eq.1:

$$
\hat{Z}\left(S_{O}\right)=\sum_{i=1}^{n} \lambda_{i} Z\left(S_{i}\right) \quad \text { Eq. } 1
$$

Where: $\mathrm{Z}\left(\mathrm{s}_{\mathrm{i}}\right)=$ the measured value at the $\mathrm{i}^{\text {th }}$ location

$\lambda \mathrm{i}=$ an unknown weight for the measured value at the $\mathrm{i}^{\text {th }}$ location

$\mathrm{s}_{0}=$ the prediction location

$\mathrm{N}=$ the number of measured values

\section{RESULTS AND DISCUSSION}

\section{Annual daily sunlight duration}

Figure 2 (a) depicts a spatial distributional pattern of mean annual daily sunlight duration and (b) depicts the mean daily annual maximum temperature $\left({ }^{\circ} \mathrm{c}\right)$ of Sindh province.

i. Maximum sunlight duration areas: The Sanghar, Umerkot and Mithi are the areas which have the highest sunlight duration. The maximum rate of reflection of solar energy in these areas is due to cloudless skies which may be the causes of maximum sunlight. 


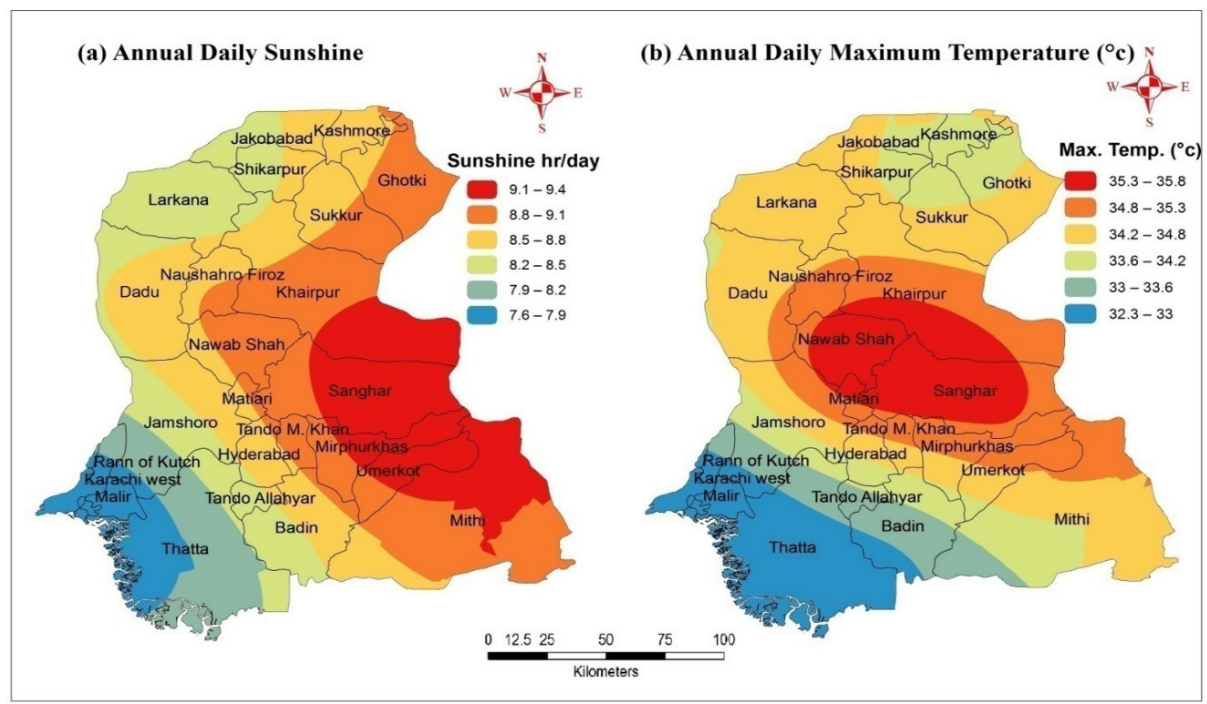

Figure 2. (a, b) spatial distribution of mean annual Sunlight hrs/day and max, air temperature $\left({ }^{\circ} \mathrm{C}\right)$.

ii. Moderate sunlight duration areas: The central and upper regions of Sindh are of moderate sunlight duration areas. The mean daily maximum temperature is high in central regions of the province. The duration of bright sunlight decreases towards the southwest.

iii. Minimum sunlight duration areas: The coastal areas of the province are of low sunlight areas because of cloudiness in the summer season. The minimum sunlight duration is at Karachi $7.6 \mathrm{hrs} /$ day.

\section{Seasonal variation in sunlight duration}

\section{Winter sunlight duration}

Figure 3 (a) depicts the spatial distributional pattern of mean winter daily sunlight duration and (b) depicts the mean daily winter maximum temperature $\left({ }^{\circ} \mathrm{C}\right)$ of the Sindh province. The highest winter sunlight duration of Sindh province is $9.4 \mathrm{hrs}$ /day, observed at Chhor, and the lowest is 7.5 hrs /day at Larkana. The winter sunlight duration of Sindh Province categorized into the following regions. 


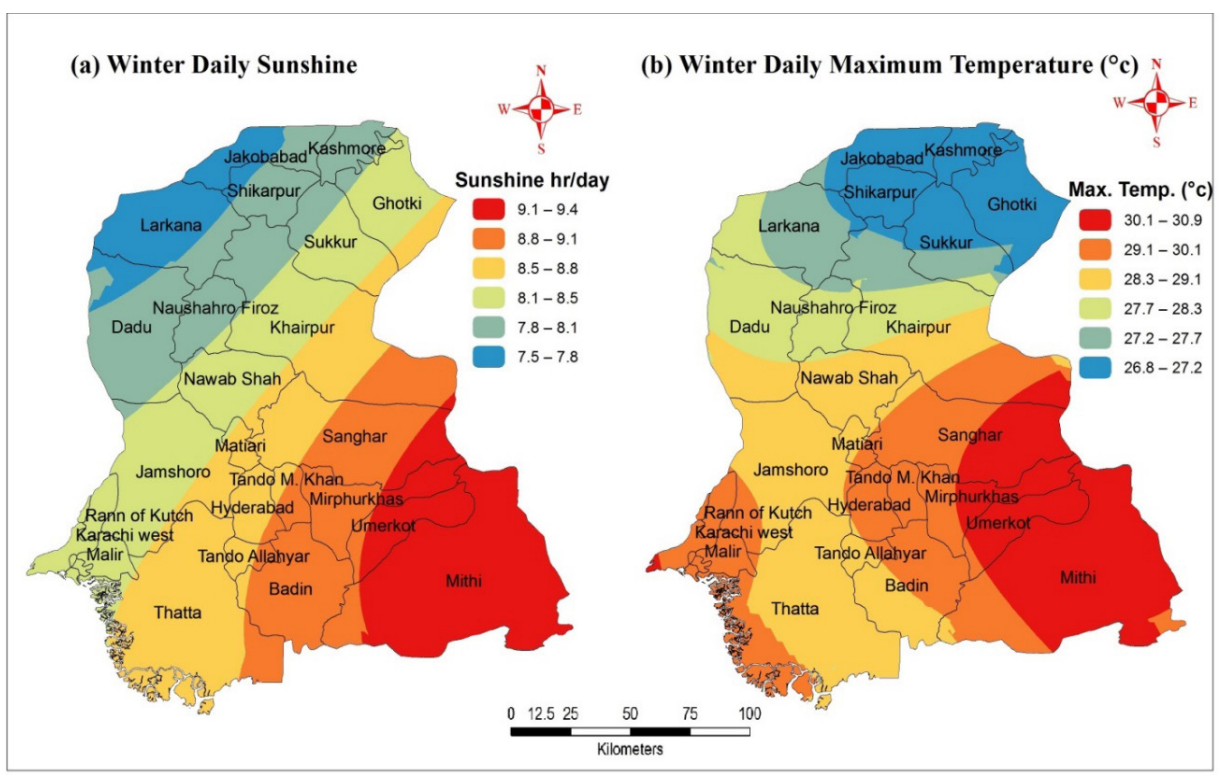

Figure 3. (a, b) Spatial distribution of mean winter Sunlight hrs /day and max. Air temperature $\left({ }^{\circ} \mathrm{C}\right)$.

i. Maximum sunlight duration areas: The region includes the Mithi and Umerkot are receiving the maximum sunlight duration in winter. The maximum winter sunlight duration of the region is due to its tropical location and clear skies. The mean daily maximum temperature remains also high in this region. The region has sunlight duration above $9.1 \mathrm{hrs} /$ day.

ii. Moderate sunlight duration areas: In winter most of the central part of the study area receives moderate sunlight duration with an average of $8 \mathrm{hrs} /$ day to $9 \mathrm{hrs} /$ day throughout the season. While in Karachi the highest sunlight duration is $8.8 \mathrm{hrs} /$ day, therefore these regions are commonly appropriate for human activities and vegetation growth.

iii. Minimum sunlight duration areas: some areas of upper Sindh fall in this region. The minimum and maximum Sunlight duration have been observed in this region which is below $7.8 \mathrm{hrs} /$ day. The mean daily maximum temperature is also comparatively low in this region, however the sunlight duration increases in winter towards the southeast of the province. 
Summer sunlight duration: The Figure 4 (a) depicts a spatial distributional pattern of mean summer daily sunlight duration and (b) depicts the mean daily summer maximum temperature in $\left({ }^{\circ} \mathrm{c}\right)$ of the Sindh province. The maximum sunlight duration in summer has been observed which is $9.1 \mathrm{hrs} /$ day at Padidan, while the minimum sunlight duration is $6.8 \mathrm{hrs} /$ day at Karachi. Meanwhile, we have categorized the summer sunlight duration of Sindh Province into the following zones.

i. Maximum sunlight duration areas: Most of the central and southeastern part of province constitutes a region of maximum sunlight duration. The mean daily maximum temperature also remains high in the central part. It has been characterized by sunlight duration over 9 hrs /day throughout the season, while the sunlight duration decreases from central part towards North West and coastal areas of the province.

ii. Moderate sunlight duration areas: Larkana, Hyderabad, Sanghar and Jamshoro have been observed as moderate sunlight duration, having (above $8.7 \mathrm{hrs} /$ day) highest sunlight duration in the upper part of study area while it decreases to $6.8 \mathrm{hrs} /$ day towards Karachi in the south.

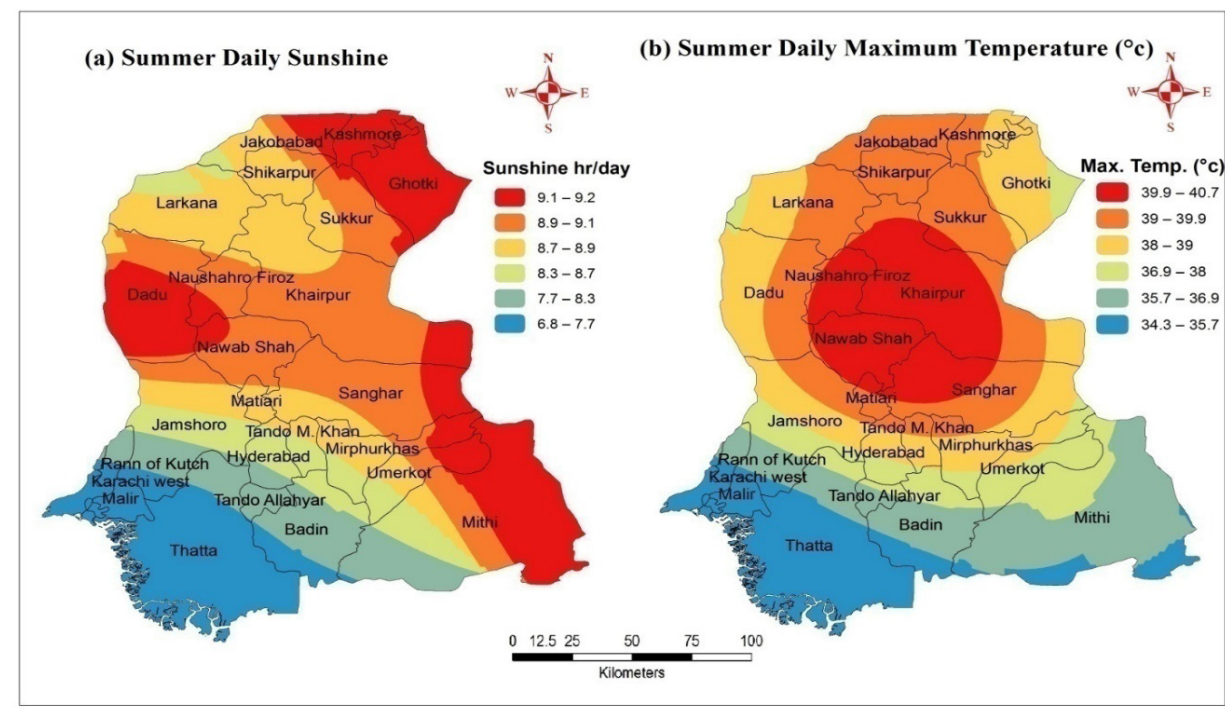

Figure 4. ( $a, b)$ spatial distribution of mean summer Sunlight hrs /day and max. air temperature $\left({ }^{\circ} \mathrm{C}\right)$. 
iii. Minimum sunlight duration areas: It has been observed that the coastal region of the province having the areas of minimum sunlight duration which is below 7 hrs / day in summer, because of high humidity, clouds and sea fogs.

\section{Relationship between sunlight duration and air temperature}

The annual and seasonal mean sunlight duration and mean daily maximum air temperature of nine meteorological stations are attributed in Table 1. The relationship between sunlight duration and the air temperature was also quantified for each annual and seasonal variation. The linear regression analysis was carried out with sunlight duration as the independent variable and maximum air temperature $\left(\operatorname{Tmax}^{\circ} \mathrm{C}\right)$ is the dependent variables for each annual and seasonal variation. For further observation and find the relationship between sunlight and air temperature, a scatter plot has been created which shows a strong positive correlation between sunlight duration and air temperature as shown in Figures (5-7). It is because the sunlight duration and air temperature are in directly proportional.

Table 1. Mean Sunlight duration and mean daily maximum air temperature $\left({ }^{\circ} \mathrm{C}\right)$.

\begin{tabular}{|c|c|c|c|c|c|c|}
\hline \multirow[b]{2}{*}{ Station } & \multicolumn{2}{|c|}{ Annual } & \multicolumn{2}{|c|}{ Winter } & \multicolumn{2}{|c|}{ Summer } \\
\hline & $\begin{array}{c}\text { Temperature } \\
\left(\operatorname{Tmax}^{\circ} \mathrm{C}\right)\end{array}$ & $\begin{array}{l}\text { Sunlight hrs } \\
\text { /day }\end{array}$ & $\begin{array}{c}\text { Temperature } \\
\left(\operatorname{Tmax}^{\circ} \mathrm{C}\right)\end{array}$ & $\begin{array}{l}\text { Sunlight hrs } \\
\text { /day }\end{array}$ & $\begin{array}{l}\text { Temperature } \\
\left(\operatorname{Tmax}^{\circ} \mathrm{C}\right)\end{array}$ & $\begin{array}{c}\text { Sunlight hrs } \\
\text { /day }\end{array}$ \\
\hline Chhor & 35.2 & 9.4 & 30.9 & 9.4 & 38.4 & 9 \\
\hline Hyderabad & 34.3 & 8.6 & 29 & 8.6 & 38 & 8.4 \\
\hline Jacobabad & 34.3 & 8.4 & 26.9 & 7.8 & 39.6 & 8.9 \\
\hline Karachi & 32.3 & 7.6 & 29.6 & 8.4 & 34.3 & 6.8 \\
\hline Nawabshah & 35.8 & 8.8 & 29 & 8.3 & 40.7 & 8.9 \\
\hline Badin & 33.2 & 8.4 & 29.1 & 8.8 & 36.1 & 7.9 \\
\hline Padidan & 35 & 9 & 27.7 & 8.3 & 40.2 & 9.2 \\
\hline Rohri & 34.2 & 8.6 & 26.8 & 8.1 & 39.6 & 8.9 \\
\hline Larkana & 34.5 & 8.2 & 27.4 & 7.5 & 39.6 & 8.6 \\
\hline
\end{tabular}




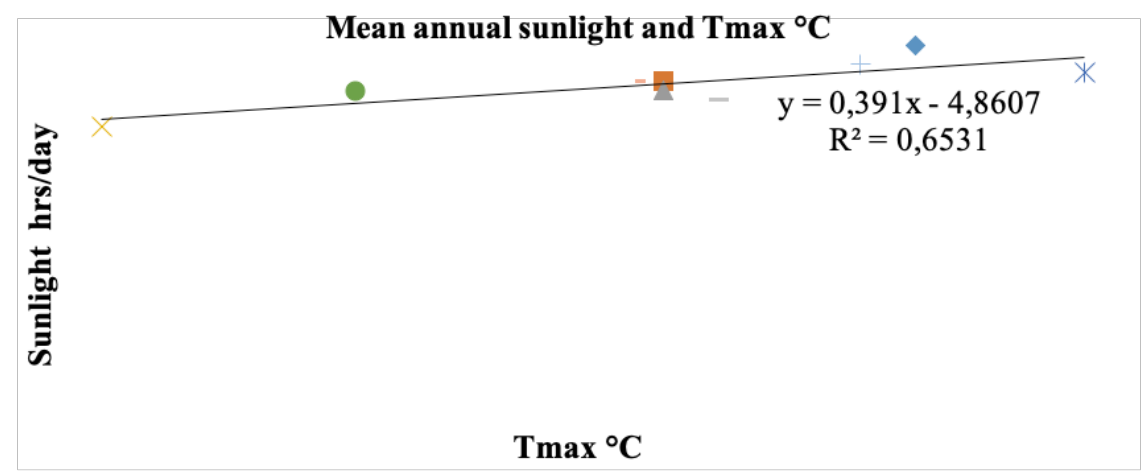

Figure 5. Scatter plot with a fitted line of mean annual air temperature versus sunlight duration.

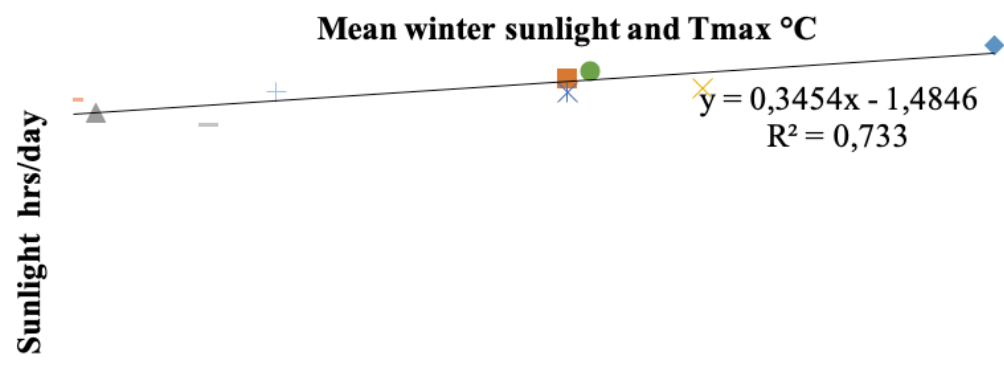

\section{$\operatorname{Tmax}{ }^{\circ} \mathrm{C}$}

Figure 6. Scatter plot with the fitted line of mean winter air temperature versus sunlight duration.

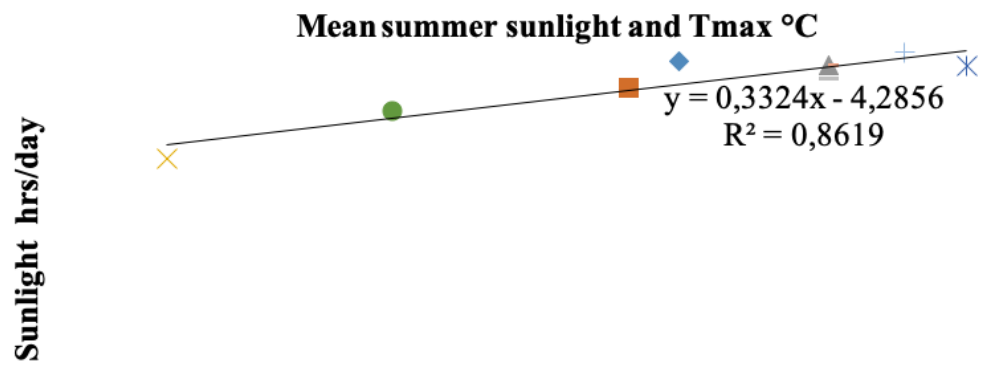

\section{$\operatorname{Tmax}{ }^{\circ} \mathbf{C}$}

Figure 7. Scatter plot with the fitted line of mean summer air temperature versus sunlight duration. 


\section{CONCLUSION}

With the help of Geographical Information System (GIS) tools the spatial variation of the mean duration of sunlight analyzed for the last thirty years through the Kriging interpolation technique. It was observed the Sindh province receives a substantial quantity of sunlight in the year and has a chance to control the energy deficiency by using alternative energy resources i.e. solar energy. The mean irradiation falling on a horizontal surface is about 3000 plus sunlight hours in a year. These conditions are ideal for photovoltaic (PV) applications and other solar applications. The mean duration of sunlight and maximum air temperature are positively correlated. The duration of sunlight in the southeastern part of the study area is longer as compared to the rest of the part, but the mean air temperature remains high in the central part of the study area. Therefore, the most appropriate site for solar power plants is the central part of the province. 


\section{REFERENCES}

Ahmed, J., Ahmed, M., Laghari, A., Lohana, W., Ali, S. \& Fatmi, Z. (2009). Public private mix model in enhancing tuberculosis case detection in District Thatta, Sindh, Pakistan. Fournal of the Pakistan Medical Association, 59(2), pp. $82-86$.

Ahmed, S., Zafran, M., Khan, F. M., Waqar, M. A. \& Hasan, Q. U. (2017). Impact of integrating wind and solar energy on vulnerable power systems. In the 2017 International Multi-topic Conference (INMIC). doi: http://dx.doi. org/10.1109/INMIC.2017.8289461

Asif, M. (2009). Sustainable energy options for Pakistan. Renewable and Sustainable Energy Reviews, 13(4), pp. 903-909. doi: http://dx.doi.org/10.1016/j. rser.2008.04.001

Bakhtiar, F. \& Ahmed, A. (2017). A review of solar energy in Pakistan: Current status and future prospects. Science, Technology, and Development, 36(3), pp. 189195.

Basir, R., Aziz, N., Ahmad, S. S. \& Wahid, A. (2013). Satellite remote sensing for identification of solar potential sites in Pakistan. International Fournal of Basic and Applied Sciences, 2(2), p. 200. doi: http://dx.doi.org/10.14419/ijbas. v2i2.896

Kabir, E., Kumar, P., Kumar, S., Adelodun, A. A. \& Kim, K. H. (2018). Solar energy: Potential and future prospects. Renewable and Sustainable Energy Reviews, 82, pp. 894-900. doi: http://dx.doi.org/10.1016/j.rser.2017.09.094

Qasim, H., Luqman, M., \& Khan, S. (2016). A study of forest land cover changes using satellite remote sensing in Thatta district Pakistan. Science International, 28(3).

Tahir, Z. \& Asim, M. (2018). Surface measured solar radiation data and solar energy resource assessment of Pakistan: A review. Renewable and Sustainable Energy Reviews, 81, pp. 2839-2861. doi: http://dx.doi.org/10.1016/j. rser.2017.06.090 
3C Tecnología. Glosas de innovación aplicadas a la pyme. ISSN: 2254-4143

Venkataraman, B. \& Elango, D. (1998). Renewable Energy Sources. Hindustan College of Engineering, Padur, India. 


\section{AUTHORS}

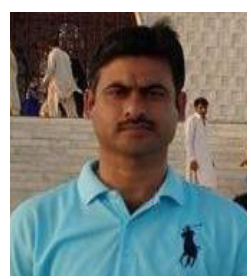

\section{Asim Nawaz}

Post graduate Student (RS \& GIS) Department of Geography University of Karachi, Pakistan.

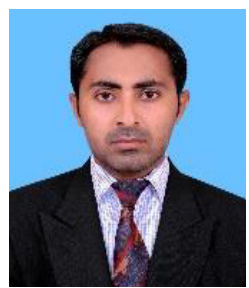

\section{Sikandar Ali}

MS (RS \& GIS) From Department of Geography University of Karachi Pakistan, Currently working as lecturer at Faculty of Engineering, Science \& Technology Indus University Pakistan.

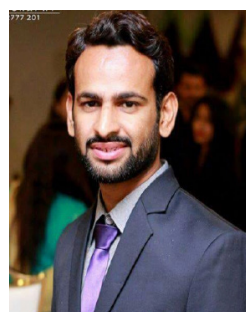

\section{Sabir Ali Kalhoro}

M. Engg (Industrial Electronics) Student Department of Electronics Engineering NED University of Engineering and Technology Karachi Pakistan.

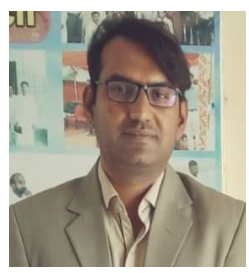

\section{Saadullah Rahoojo}

Lecturer at Department of Geography, University of Sindh Jamshoro, Pakistan.

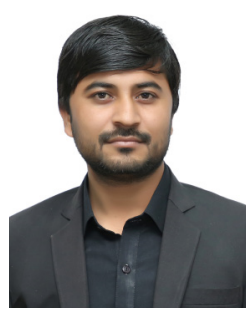

\section{Muneer Abbas}

Post graduate Student Department of Energy and Environment Hamdard University Karachi, Pakistan. 


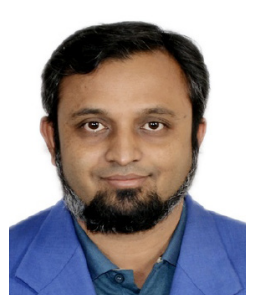

\section{Muhammad Shahid}

Lecturer, Department of Electronic Engineering.

Dawood University of Engineering and Technology, Karachi, Pakistan. 
Edición Especial Special Issue Mayo 2019

DOI: http://dx.doi.org/10.17993/3ctecno.2019.specialissue2.468-485 